OPEN ACCESS

Edited by: Ana Belen Lopez-Rodriguez, Trinity College, Dublin, Ireland

Reviewed by: Víctor M. Navarro, Harvard Medical School,

United States

Ivana Bjelobaba,

University of Belgrade, Serbia

*Correspondence:

Roger Walz

rogerwalz@hotmail.com

Specialty section:

This article was submitted to Neuroendocrine Science,

a section of the journal

Frontiers in Endocrinology

Received: 07 November 2017

Accepted: 22 January 2018

Published: 13 February 2018

Citation:

Hohl A, Zanela FA, Ghisi G, Ronsoni MF, Diaz AP, Schwarzbold ML, Dafre AL, Reddi B, Lin K, Pizzol FD and Walz R (2018)

Luteinizing Hormone and Testosterone Levels during Acute Phase of Severe Traumatic Brain

Injury: Prognostic Implications for Adult Male Patients.

Front. Endocrinol. 9:29. doi: 10.3389/fendo.2018.00029

\section{Luteinizing Hormone and Testosterone Levels during Acute Phase of Severe Traumatic Brain Injury: Prognostic Implications for Adult Male Patients}

\author{
Alexandre Hohl1,2, Fernando Areas Zanela ${ }^{1}$, Gabriela Ghisi ${ }^{2}$, Marcelo Fernando Ronsoni ${ }^{1,2}$, \\ Alexandre Paim Diaz ${ }^{1,3}$, Marcelo Liborio Schwarzbold ${ }^{1,3}$, Alcir Luiz Dafre ${ }^{1,4}$, \\ Benjamin Reddi5,6, Kátia Lin ${ }^{1,7}$, Felipe Dal Pizzol ${ }^{1,8}$ and Roger Walz ${ }^{1,7 *}$ \\ ${ }^{1}$ Centro de Neurociências Aplicadas (CeNAp), Hospital Universitário (HU), Universidade Federal de Santa Catarina (UFSC), \\ Florianópolis, Brazil, ${ }^{2}$ Serviço de Endocrinologia e Metabologia, Departamento de Clínica Médica, Hospital Universitário \\ (HU), Universidade Federal de Santa Catarina (UFSC), Florianópolis, Brazil, ${ }^{3}$ Serviço de Psiquiatria, Departamento de Clínica \\ Médica, Hospital Universitário (HU), Universidade Federal de Santa Catarina (UFSC), Florianópolis, Brazil, ${ }^{4}$ Departamento de \\ Bioquímica, Universidade Federal de Santa Catarina (UFSC), Florianópolis, Brazil, ${ }^{5}$ Intensive Care Unit, Royal Adelaide \\ Hospital, Adelaide, SA, Australia, ${ }^{6}$ School of Medicine, University of Adelaide, Adelaide, SA, Australia, ${ }^{7}$ Serviço de \\ Neurologia, Departamento de Clínica Médica, Hospital Universitário (HU), Universidade Federal de Santa Catarina (UFSC), \\ Florianópolis, Brazil, ${ }^{8}$ Laboratório de Fisiopatologia Experimental, Universidade do Extremo Sul Catarinense \\ (UNESC), Criciúma, Brazil
}

Traumatic brain injury (TBI) is a worldwide core public health problem affecting mostly young male subjects. An alarming increase in incidence has turned TBI into a leading cause of morbidity and mortality in young adults as well as a tremendous resource burden on the health and welfare sector. Hormone dysfunction is highly prevalent during the acute phase of severe TBI. In particular, investigation of the luteinizing hormone (LH) and testosterone levels during the acute phase of severe TBI in male has identified a high incidence of low testosterone levels in male patients (36.5-100\%) but the prognostic significance of which remains controversial. Two independent studies showed that normal or elevated levels of LH levels earlier during hospitalization are significantly associated with higher mortality/morbidity. The association between LH levels and prognosis was independent of other predictive variables such as neuroimaging, admission Glasgow coma scale, and pupillary reaction. The possible mechanisms underlying this association and further research directions in this field are discussed. Overall, current data suggest that $\mathrm{LH}$ levels during the acute phase of TBI might contribute to accurate prognostication and further prospective multicentric studies are required to develop more sophisticated predictive models incorporating biomarkers such as $\mathrm{LH}$ in the quest for accurate outcome prediction following TBI. Moreover, the potential therapeutic benefits of modulating $\mathrm{LH}$ during the acute phase of TBI warrant investigation.

Keywords: traumatic brain injury, gonadotrophic axis, luteinizing hormone, testosterone, prognosis

\section{TRAUMATIC BRAIN INJURY (TBI) EPIDEMIC}

Traumatic brain injury is a worldwide significant public health problem and following an alarming increase in incidence has become the leading cause of morbidity and mortality of young male adults (1-6). In 2014-2015, the mean annual incidence of severe TBI hospitalizations, in the Brazilian 
city of Florianópolis (population 460,000), was 7.09/100,000 habitants with an associated hospital mortality of 3.54/100,000 habitants (Zanela et al., unpublished data). Among the survivors in our unit, $33.3 \%$ developed personality changes, $27.3 \%$ major depressive disorders, $15.1 \%$ anxiety disorders, and $9 \%$ alcohol dependence, significantly impacting quality of life (3) and work capacity (4). Long-term cognitive impairment is also highly prevalent, being clinically meaningful for more than $50 \%$ of our patients who survived a severe TBI $(6,7)$.

\section{CHRONIC HYPOPITUITARISM AND TBI}

Described in 1918 (8), partial or complete hypopituitarism is a potential consequence of TBI $(9,10)$. There are several mechanisms by which TBI can cause hypothalamus-pituitary dysfunction, including hypoxic insult or direct mechanical injury to the hypothalamus, pituitary stalk or the gland itself, compression from hemorrhage, edema or increased intracranial pressure, and vascular injury to the hypothalamus or the pituitary gland (10-13).

Long-term morbidity in TBI survivors typically includes somatic, psychiatric, cognitive and neurological symptoms $(3-5,7,14)$. These TBI-related sequelae can cover subtle signs of hypopituitarism, resulting in underestimation of posttraumatic hypopituitarism that also may aggravate the TBI-related morbidity itself (12). There are limited data available on TBI survivors regarding either the impact of hypopituitarism or the role of replacing hormones such as testosterone after TBI. Longer prospective multicentric studies are needed to monitor natural course of pituitary dysfunction in TBI and to follow long-term effects of hormonal replacement.

\section{LH AS BIOMARKER OF MORTALITY IN SEVERE TBI}

The impact of hormone replacement for TBI-related hypopituitarism during the initial period after the injury depends on the type hormone deficiency. For example, unrecognized acute adrenocorticotropic hormone (ACTH) and cortisol deficiency or antidiuretic hormone deficiency (diabetes insipidus), can be life threatening (12). However, the prognostic implications for the low levels of luteinizing hormone (LH) and testosterone levels immediately following severe TBI remain incompletely understood. We reviewed the 10 articles available in PubMed (see Table 1) that evaluated LH and testosterone levels in adult male patients during hospitalization for severe TBI $(9,10$, 14-21). In nine studies $(9,10,13-21)$, hormone levels were determined in the first 10 days after TBI. In one study (14), levels were measured up to 20 days after the injury. Five studies included at least 30 male patients with severe TBI and analyzed $\mathrm{LH}$ and testosterone levels over 1 to 12 days after the injury $(10,14,17,18,20)$. LH levels were low in $36.7-58.6 \%$ of patients and testosterone in $35.5-100 \%$ of patients. In our patients, both $\mathrm{LH}$ and testosterone levels decreased over the initial 3 days following the injury the (Figures $\mathbf{1 A}, \mathbf{B}$, respectively). In our patients, the Pearson's correlation showed that in the first day the serum testosterone levels were significantly $(p=0.04)$ and positively correlated $(r=0.31)$ with serum testosterone (data not shown). There was no significant correlation between LH and testosterone levels on day $2(r=0.24, p=0.09)$ or day 3 $(r=0.20, p=0.18)$ post severe TBI (data not shown). The loss of this positive correlation suggests a time-dependent dissociation between LH and testosterone shortly after the injury.

Diagnostic and therapeutic decisions are based on a clinicians estimate of patient's prognosis. Prognostic models, derived from statistical analysis of patient-related clinical, demographic, injury specific or biomarker variables, and clinical outcome, can increase the accuracy of clinical judgment regarding likely outcome following TBI $(1,5,6,22-24)$. We investigated whether serum levels of several hormones in the acute phase of severe TBI [Glasgow coma scale (GCS) $\leq 8$ ], including free thyroxine (free T4), thyroid-stimulating hormone, LH, follicle-stimulating hormone, total and free testosterone, growth hormone, and insulin-like growth factor 1 were independently associated with hospital mortality in our patients $(n=60$, all males) $(10,11)$. The protocol study was approved by the Human Research Ethics Committee of the Universidade Federal de Santa Catarina, UFSC (Process 163/2005 and 802.795). Written informed consent was obtained from the families. Gunshot injury victims and patients progressing to brain death within $24 \mathrm{~h}$ of admission were excluded. The primary outcome variable was hospital mortality. Additional variables analyzed were age, computed tomography (CT) findings, presence of associated trauma (thorax and/or abdomen), admission GCS score and pupil examination at admission. CT findings were classified in six categories according to Marshall classification and presence of subarachnoid hemorrhage. Hormone analyses undertaken at a median of 10 (IQR 6-18) h $(n=57)$ and 30 (IQR 22-37) h $(n=55)$ after TBI have been previously described (10). Additional analysis carried out in the same sample of patients $70 \mathrm{~h}$ after TBI are included in the present work (Sample 3, IQ range 53-77, $n=53$ ). Of the investigated hormones, only LH showed a significant association with hospital mortality. As showed in Figure 1A, the mean level of serum LH was significantly lower in survivors than in non-survivors. After controlling for demographic, clinical, radiological, and neurosurgical variables by multiple binary regression, the association between normal or elevated LH levels observed at a median of 10 and $30 \mathrm{~h}$ after the injury and hospital mortality did not reach statistical significance when compared to patients with low $\mathrm{LH}$ levels (OR $3.7 p=0.08$ at $10 \mathrm{~h}$ and $3.9 p=0.06$ at $30 \mathrm{~h}$ Figure 1C). When LH levels were determined $70 \mathrm{~h}$ after the injury, normal or increased LH levels were significantly associated with hospital mortality when compared to lower LH levels (OR 8.4, CI 95\% $1.72-42.2, p=0.008$ ). The observed association between normal or increased LH levels and hospital mortality was independent of the distribution of other investigated variables. Low GCS score and pupil abnormalities on admission also remained independently associated with mortality (not shown). Other studies evaluating gonadotrophic hormone levels in the acute phase of TBI are summarized in Table 1. Association between the outcome and hormone levels were not reported in five $(9,15,17,18,20,25)$. One study showed no association between the LH levels and prognosis, but a type II error related to the small 
TABLE 1 | Previous studies showing gonadotrophic axis hormones profile during acute phase of severe TBI in male.

\begin{tabular}{|c|c|c|c|}
\hline Reference & $\begin{array}{l}\text { Time-course } \\
\text { after TBI }\end{array}$ & Results in male & Clinical correlations and significance for mortality and morbidity \\
\hline Agha et al. (14) & $\begin{array}{l}7 \text { to } 20 \text { days } \\
\text { (median } 12 \text { ) }\end{array}$ & $\begin{array}{l}\text { Low testosterone levels in } 79 \% \text { of } \\
\text { patients }\end{array}$ & $\begin{array}{l}\text { Positive correlation between testosterone and TBI and GCS }(r=0.32 \text {, } \\
p=0.048) \text {; } \\
\text { Association between testosterone and prognosis were not analyzed }\end{array}$ \\
\hline Cernak et al. (9) & Up to 7 days & $\begin{array}{l}\text { Testosterone decrease in } 2 \text { days } \\
\text { after TBI }\end{array}$ & $\begin{array}{l}\text { Association between hormone levels and TBI severity and prognosis were not } \\
\text { analyzed }\end{array}$ \\
\hline Dalwadi et al. (15) & $24 \mathrm{~h}$ & Low testosterone in $63.5 \%$ of patients & $\begin{array}{l}\text { Correlation between testosterone and GCS did not reach significance } \\
\text { No association between LH and testosterone and mortality } \\
\text { Imbalances in the distribution of other predictors were not described } \\
\text { Small sample size of severe TBI patients }\end{array}$ \\
\hline Hohl et al. (10) & Up to $48 \mathrm{~h}$ & $\begin{array}{l}\text { Low LH in } 36.8 \% \text { of patients in the } 1 \text { st } \\
\text { day and } 41.8 \% \text { in the } 2 \text { nd day } \\
\text { Low testosterone in } 36.5 \% \text { of patients } \\
\text { in the } 1 \text { st day and } 73.1 \% \text { in the } 2 \text { nd } \\
\text { day }\end{array}$ & $\begin{array}{l}\text { Trend for independent association between normal or elevated LH mortality } \\
(p=0.08) \\
\text { Distribution of other predictive variables and hormones were not controlled } \\
\text { The possibility of type II error related to the small sample size should } \\
\text { be considered }\end{array}$ \\
\hline Kleindienst et al. (21) & $\begin{array}{l}\text { Admission Day } \\
1 \text { and } 7\end{array}$ & $\begin{array}{l}\text { In comparison to admission, the mean } \\
\mathrm{LH} \text { and testosterone levels decrease on } \\
\text { day } 3 \text { and } 7 \text { after TBI }\end{array}$ & $\begin{array}{l}\text { Association between injury severity and low testosterone and LH levels on day } 3 \\
\text { Higher LH levels associated with number of lesions on the CT scan } \\
\text { Association between testosterone and prognosis were not analyzed } \\
\text { Small sample size of patients with severe TBI }\end{array}$ \\
\hline Klose et al. (16) & Up to 12 days & Lower LH levels and testosterone & $\begin{array}{l}\text { Correlation between low testosterone and TBI severity } \\
\text { Wide range of time course between TBI and blood sampling for hormone analysis } \\
\text { Association between hormones and prognosis were not analyzed } \\
\text { Small sample size of patients with severe TBI }\end{array}$ \\
\hline Hari Kumar et al. (17) & $24 \mathrm{~h}$ & Low testosterone in $37.5 \%$ of patients & $\begin{array}{l}\text { No association between LH or testosterone and GCS } \\
\text { Association between hormones and prognosis were not analyzed } \\
\text { Small sample size of patients with severe TBI }\end{array}$ \\
\hline Olivecrona et al. (18) & Days 1 and 4 & $\begin{array}{l}\text { Low testosterone in } 82.1 \text { and } 100 \% \text { of } \\
\text { patients at the } 1 \text { st and } 4 \text { th day after the } \\
\text { TBI respectively } \\
\text { Low LH in } 55.2 \% \text { and } 58.6 \% \text { of } \\
\text { patients in the } 1 \text { st and } 4 \text { th days after } \\
\text { the TBI respectively }\end{array}$ & $\begin{array}{l}\text { Higher LH on day } 1 \text { (but not day 4) in patients with unfavorable outcome } \\
\text { (morbidity and mortality) } 3 \text { months after TBI } \\
\text { Regression models combining LH levels and ICPmax showed significant } \\
\text { association with prognosis and ICPmax still was the main predicting factor } \\
\text { (AUC for this model was not shown) } \\
\text { Prognostic models including other predictors (GCS, pupils, sub-arachnoid } \\
\text { hemorrhage) and LH levels were not analyzed by the authors }\end{array}$ \\
\hline Tanriverdi et al. (19) & $24 \mathrm{~h}$ & $\begin{array}{l}\text { Significant lower testosterone levels, } \\
\text { but not LH, in patients with severe TBI }\end{array}$ & $\begin{array}{l}\text { Positive correlation between testosterone and GCS } \\
\text { Association between testosterone and prognosis were not analyzed } \\
\text { Small sample size of patients with severe TBI }\end{array}$ \\
\hline Wagner et al. (21) & Day 1 to 9 & $\begin{array}{l}\text { Low LH in } 50 \% \text { of patients } \\
\text { Low testosterone in } 91 \% \text { of patients } \\
\text { LH and testosterone decline were seen } \\
\text { in non-head injured extracranial trauma }\end{array}$ & $\begin{array}{l}\text { LH or testosterone during acute phase of injury was not associated with the } \\
\text { prognosis (GOS) } 6 \text { months after the TBI }\end{array}$ \\
\hline
\end{tabular}

TBI, traumatic brain injury; GCS, Glasgow coma scale; GOS, Glasgow outcome scale; ISS, injury severity score; Marshal grade, Marshal Computed Tomography Classification; ICPmax, maximal intracranial pressure.

sample size of cases with severe TBI needs to be considered (16). A Swedish study found a similar association between low LH levels in the acute phase of severe TBI and lower mortality and morbidity ( $n=45 ; 30$ males). They also evaluated a prediction model combining LH levels with intracranial pressure although other predictive variables like GCS and pupils' abnormalities were not included in their model (Table 1) (19).

Another study including 88 patients with severe TBI investigated the association between LH levels determined in the acute phase and the Glasgow Outcome Scale (GOS) 6 months or more after the injury (21). The authors dichotomized the outcome according to the GOS score as favorable $(>4)$ or unfavorable $(\leq 4)$ where $5=$ good recovery, $4=$ mild disability, $3=$ severe disability, $2=$ vegetative state, and $1=$ death. They found no association between LH level and 6 month GOS. In addition to the use of a biomarker to distinguish patients likely to have a good (GOS 5) vs. poor (GOS 2-4) outcome, a biomarker which can predict increased mortality would also be valuable. Accordingly, it would be interesting to analyze the predictive value of normal or higher LH levels for mortality in a patient cohort such as that studied by Wagner et al. (21). In our patients, LH levels determined earlier after the injury, alone or in combination with admission GCS or pupils' examination, showed an elevated specificity (87-100\%) but low sensitivity $(<50 \%)$ to predict hospital mortality (data not shown).

Data regarding the relationship between the severity of TBI (based on the admission GCS) and testosterone levels are conflicted. Two studies including mild, moderate, and 


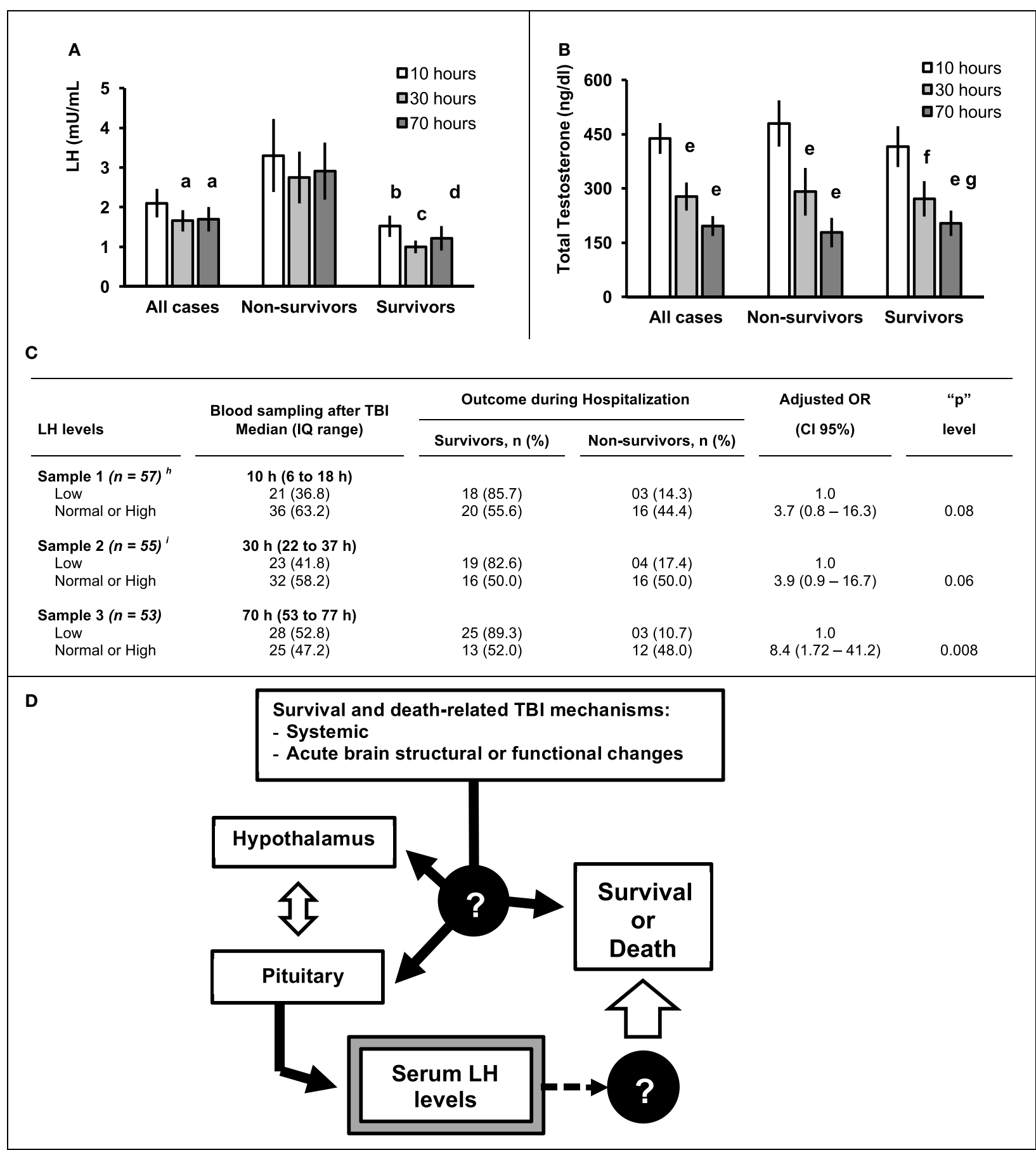

FIGURE 1 | Serum level (mean \pm SE) of luteinizing hormone (LH) (A) or total testosterone (B) determined in the Sample $1(n=57$, median of $10 \mathrm{~h}$ after traumatic brain injury (TBI), IQ range $=6-18 \mathrm{~h}$ ), Sample $2(n=55$, median of $30 \mathrm{~h}$ after TBI, IQ range $=22-37)$, and Sample $3(n=53$, median of $70 \mathrm{~h}$ after TBI, IQ range 53-77) according to hospital mortality. (C) Table showing the hospital mortality according to the LH levels adjusted for admission Glasgow coma scale and pupils' examination. The normal or high LH levels in sample $1(p=0.08)$ and $2(p=0.06)$ showed a trend for independent association with mortality and a significant $(p=0.008)$ independent association in the Sample 3. (D) The survival and death-related TBI mechanisms may affects hypothalamus and hypophysis resulting in the LH levels changes (black arrows). It is unknown if the LH level itself affects the prognosis (dashed arrows) or is only an epiphenomenon without a cause-effect relationship with the patients' prognosis. aSignificant difference $(p=0.04)$ between Sample 2 and Sample 1 and Sample 3 and Sample 1 by Paired-Samples " $T$ " test; "Significant difference between survivors and non-survivors for " $p$ " $<0.02$ (Sample 1) by Student " $t$ " test; "Significant difference between survivors and non-survivors for " $p$ " $=0.002$ (Sample 2) by Student " $t$ " test; "Significant difference between survivors and non-survivors for " $p$ " $=0.01$ (Sample 3) by Student " $t$ " test; "Significant difference from the Sample 1 for " $p$ " $<0.0001$ by Paired-Samples " $T$ " test; 'Significant difference from the Sample 1 for " $p$ " $=0.02$ by PairedSamples " $T$ " test; "Significant difference from the Sample 1 for " $p$ " $=0.002$ by Paired-Samples " $T$ " test. h.,Results previously published by Hohl et al. (10) and included as a part of his PhD Thesis in Medical Sciences (11). 
severe TBI showed a positive correlation between testosterone and GCS score (lower testosterone in lower GCS scores) $(15,17)$. However, this association was not confirmed by two other groups $(16,18)$. In studies including only severe TBI patients $(10,11,19)$, or predominantly TBI patients (21), testosterone levels did not correlate with GCS. This may reflect the high percentage of abnormally low serum testosterone levels in patients included in the studies (21). Of note, severe TBI patients, testosterone levels neither correlate with Maximal Intracranial Pressure nor with the Minimal Cerebral Perfusion Pressure (19). Moreover, the association between testosterone levels and mortality or morbidity was significant in one study (19), not significant in four studies $(10,16,21)$ and not analyzed in other six $(9,15,17,18,20,25)$.

\section{DOES LH LEVEL AFFECT MORBIDITY AND MORTALITY IN SEVERE TBI PATIENTS?}

Association studies can enhance diagnostic strategies, improve prognostic models, and highlight therapeutic targets of disease. If the observed findings in patients from Brazil $(10,11)$ and Sweden (19) are confirmed in other populations, LH levels can become a useful biomarker for mortality or morbidity in severe TBI patients. However, association studies do not prove a causative relationship between the predictive variable and the investigated end-point but can inform subsequent interventional, double blind, randomized, controlled, multicentre, studies designed to evaluate whether manipulating the gonadotrophic axis can improve outcomes from TBI.

The observed high/normal LH levels in patients at high risk of mortality could relate to a deleterious effect of $\mathrm{LH}$, or a protective mechanism activated in patients with high risk for death. A third possibility is that changes in the LH levels during acute phase of severe TBI in males are merely a concomitant epiphenomenon with other physiological changes directly affecting the mortality in severe TBI.

The hypothalamus-pituitary axis can be directly injured through the mechanical impact or hemodynamic disturbance of a TBI. In addition, brain dysfunction related to secondary insults (6), including contributions from inflammatory, immunologic, and oxidative stress mechanisms $(22,23,26,27)$ can also affect the hypothalamus and pituitary by as yet unclear mechanisms affecting the severe TBI prognosis (Figure 1D).

As an example, we showed that elevated levels of the antiinflammatory and neuroprotective interleukin IL-10 (>90 pg/mL) in the acute phase of severe TBI (10 and $30 \mathrm{~h}$ after the injury) was associated with 5 to 6 times higher risk of hospital mortality, independent of other variables including admission CT scan, GCS, and pupillary activity examination (23). One study previously provided a direct evidence in humans of a neuroanatomical pathway coupled with the peripheral immune system through IL-10 (28). The observed association between high IL-10 levels and higher mortality in our patients may occur, at least in part, because IL-10 can be a marker of "sympathetic" dysfunction in patients with severe TBI and worse prognosis. It was previously demonstrated that IL-10 levels increase when brainstem lesions result in sympathetic activation as catecholamines stimulate monocytes and trigger IL-10 release (28). A similar rationale may underlie the association of LH levels with mortality; sustained normal or elevated LH levels during the acute phase of severe TBI may relate to specific structural brain lesions or even systemic response also related to patients' mortality.

It has been demonstrated that substance P (SP) induces LH release in animals and healthy men $(29,30)$. SP mediates the vascular permeability and edema formation that contributes to increased intra-cranial pressure after acute brain injury (31). Furthermore, serum levels of SP are associated with injury severity and mortality in patients with severe TBI (32). Taken together with the anatomical juxtaposition between the SP and gonadotrophin-releasing hormone $(\mathrm{GnRH})$ systems in the human diencephalon, these results suggest a possible link between SP release and $\mathrm{GnRH} / \mathrm{LH}$ release not only in physiologic $(29,30)$ but also pathological conditions like TBI (32). If LH itself affects the TBI prognosis or merely a marker of SP activity is an important point for further investigation.

Various animal models have been used for TBI research (33-35) and associations between TBI and hormone levels, including testosterone, have been replicated in rodents (36). However, drugs that have appeared to be neuroprotective in small animals have all failed to improve outcomes in human phase II or phase III clinical trials (31). Considering the complex mechanisms involved in the primary and secondary TBI-related hypothalamic and pituitary dysfunction, the use of TBI models including rodents $(33,34,36)$ and large animals may be required to properly test the effects of LH and SP on TBI prognosis (35).

\section{CONCLUSION AND FUTURE PERSPECTIVES}

The observation that hypogonadism is common in the acute phase of severe TBI in males across a range of different populations provides compelling evidence that this is true and potentially important phenomenon. Nevertheless, an association between testosterone levels and the male patients' prognosis after TBI remains controversial. The association between normal or elevated LH levels in the acute phase of severe TBI and male mortality was replicated by two independent studies and the association with patients' morbidity in one of them. The association between LH levels and prognosis in females, pediatric, and older patients remains unknown. If confirmed in other populations by prospective multicentre studies, the measurement of serum LH during the acute phase of injury has potential to become a useful prognostic marker of severe TBI. Prognostic models including LH levels during the acute TBI phase, in combination with other biomarkers, may also be useful to identify collinearity between LH levels and other neuro-humoral, immunologic, and endocrine biomarkers (27). Finally, the investigation of the LH as a therapeutic target in animal models of TBI is challenges for further translation research in TBI.

\section{ETHICS STATEMENT}

The protocol study was approved by the Human Research Ethics Committee of the Universidade Federal de Santa Catarina, UFSC 
(Process 163/2005 and 802.795). Written informed consent was obtained from the families.

\section{AUTHOR CONTRIBUTIONS}

$\mathrm{AH}, \mathrm{FZ}, \mathrm{GG}$, and MR, literature revision, data collection, manuscript writing; APD, MS, AD, KL, and FP, manuscript writing; RW, literature revision, manuscript writing, manuscript design, statistics analysis; $\mathrm{BR}$, literature revision, manuscript writing, answer to reviewers.

\section{REFERENCES}

1. Martins ET, Linhares MN, Sousa DS, Schroeder HK, Meinerz J, Rigo LA, et al. Mortality in severe traumatic brain injury: a multivariated analysis of 748 Brazilian patients from florianópolis city. J Trauma (2009) 67:85-90. doi:10.1097/TA.0b013e318187acee

2. de Silva MJ, Roberts I, Perel P, Edwards P, Kenward MG, Fernandes J, et al. Patient outcome after traumatic brain injury in high, middle and low-income countries: analysis of data on 8927 patients in 46 countries. Int J Epidemiol (2009) 38:452-8. doi:10.1093/ije/dyn189

3. Diaz AP, Schwarzbold ML, Thais ME, Hohl A, Bertotti MM, Schmoeller R, et al. Psychiatric disorders and health-related quality of life after severe traumatic brain injury: a prospective study. J Neurotrauma (2012) 29:1029-37. doi:10.1089/neu.2011.2089

4. Diaz AP, Schwarzbold ML, Thais ME, Cavallazzi GG, Schmoeller R, Nunes JC, et al. Personality changes and return to work after severe traumatic brain injury: a prospective study. Rev Bras Psiquiatr (2014) 36:213-209. doi:10.1590/ 1516-4446-2013-1303

5. de Oliveira Thais ME, Cavallazzi G, Formolo DA, deCastro LD, Schmoeller R, Guarnieri R, et al. Limited predictive power of hospitalization variables for long-term cognitive prognosis in adult patients with severe traumatic brain injury. J Neuropsychol (2014) 8:125-39. doi:10.1111/jnp.12000

6. Lingsma HF, Roozenbeek B, Steyerberg EW, Murray GD, Maas AI. Early prognosis in traumatic brain injury: from prophecies to predictions. Lancet Neurol (2010) 9:543-54. doi:10.1016/S1474-4422(10)70065-X

7. De Souza RL, Thais ME, Cavallazzi G, Paim Diaz A, Schwarzbold ML, Nau AL, et al. Side of pupillary mydriasis predicts the cognitive prognosis in patients with severe traumatic brain injury. Acta Anaesthesiol Scand (2015) 59:392-405. doi:10.1111/aas.12447

8. Hohl A, Mazzuco TL, Coral MH, Schwarzbold M, Walz R. Hypogonadism after traumatic brain injury. Arq Bras Endocrinol Metabol (2009) 53:908-14. doi:10.1590/S0004-27302009000800003

9. Cernak I, Savic VJ, Lazarov A, Joksimovic M, Markovic S. Neuroendocrine responses following graded traumatic brain injury in male adults. Brain Inj (1999) 13:1005-15. doi:10.1080/026990599121016

10. Hohl A, Ronsoni MF, Debona R, Ben J, Schwarzbold ML, Diaz AP, et al. Role of hormonal levels on hospital mortality for male patients with severe traumatic brain injury. Brain Inj (2014) 28:1262-9. doi:10.3109/02699052.2014. 915986

11. Hohl A. Associação entre os níveis plasmáticos hormonais e o prognóstico de pacientes masculinos vítimas de traumatismo crânio encefálico grave. Florianópolis, SC: Tese de Doutorado, Universidade Federal de Santa Catarina (2014). p. 1-86.

12. Garrahy A, Sherlock M, Thompson CJ. Neuroendocrine surveillance and management of neurosurgical patients. Eur J Endocrinol (2017) 176:R217-33. doi:10.1530/EJE-16-0962

13. Hohl A, Daltrozo JB, Pereira CG, Weber TR, Pinto HF, Gullo Jda S, et al. Late evaluation of the pituitary-gonadal axis in survivors of severe traumatic brain injury. Arq Bras Endocrinol Metabol (2009) 53:1012-9. doi:10.1590/ S0004-27302009000800016

14. Schwarzbold M, Diaz A, Martins ET, Rufino A, Amante LN, Thais ME, et al. Psychiatric disorders and traumatic brain injury. Neuropsych Dis Treat (2008) 4:797-816.

\section{FUNDING}

This work was supported by PRONEX Program (NENASC Project process 56802/2010) and PPSUS Program (TO 201302248) of FAPESC-CNPq-MS, Santa Catarina Brazil. RW, ALD, KL, and FP are Researchers Fellows from CNPq (Brazilian Council for Scientific and Technologic Development, Brazil). FZ received a fellowship for his Ph.D. degree study from Fundação de Amparo à Pesquisa do Estado do Amazonas (FAPEAM).

15. Agha A, Rogers B, Mylotte D, Taleb F, Tormey W, Phillips J, et al. Neuroendocrine dysfunction in the acute phase of traumatic brain injury. Clin Endocrinol (2004) 60:584-91. doi:10.1111/j.1365-2265.2004.02023.x

16. Dalwadi PP, Bhagwat NM, Tayde PS, Joshi AS, Varthakavi PK. Pituitary dysfunction in traumatic brain injury: is evaluation in the acute phase worthwhile? Indian J Endocrinol Metab (2017) 21:80-4. doi:10.4103/ 2230-8210.196018

17. Klose M, Juul A, Struck J, Morgenthaler NG, Kosteljanetz M, Feldt-Rasmussen U. Acute and long-term pituitary insufficiency in traumatic brain injury: a prospective single-centre study. Clin Endocrinol (2007) 67:598-606. doi:10.1111/j.1365-2265.2007.02931.x

18. Hari Kumar KVS, Swamy M, Khan M. Prevalence of hypothalamo pituitary dysfunction in patients of traumatic brain injury. Indian J Endocrinol Metab (2016) 20:772-8. doi:10.4103/2230-8210.192917

19. Olivecrona Z, Dahlqvist P, Koskinen LO. Acute neuro-endocrine profile and prediction of outcome after severe brain injury. Scand J Trauma Resusc Emerg Med (2013) 21:33. doi:10.1186/1757-7241-21-33

20. Tanriverdi F, Senyurek H, Unluhizarci K, Selcuklu A, Casanueva FF, Kelestimur F. High risk of hypopituitarism after traumatic brain injury: a prospective investigation of anterior pituitary function in the acute phase and 12 months after trauma. J Clin Endocrinol Metab (2006) 91:2105-11. doi:10.1210/ jc. 2005-2476

21. Wagner AK, McCullough EH, Niyonkuru C, Ozawa H, Loucks TL, Dobos JA, et al. Acute serum hormone levels: characterization and prognosis after severe traumatic brain injury. J Neurotrauma (2011) 28:871-88. doi:10.1089/ neu.2010.1586

22. Gullo Jda S, Bertotti MM, Silva CC, Schwarzbold M, Diaz AP, Soares FM, et al. Hospital mortality of patients with severe traumatic brain injury is associated with serum PTX3 levels. Neurocrit Care (2011) 14:194-9. doi:10.1007/ s12028-010-9462-y

23. Schneider Soares FM, Menezes de Souza N, Libório Schwarzbold M, Paim Diaz A, Costa Nunes J, Hohl A, et al. Interleukin-10 is an independent biomarker of severe traumatic brain injury prognosis. Neuroimmunomodulation (2012) 19:377-85. doi:10.1159/000342141

24. de Oliveira Thais MER, Cavallazzi G, Schwarzbold ML, Diaz AP, Ritter C, Petronilho F, et al. Plasma levels of oxidative stress biomarkers and long-term cognitive performance after severe head injury. CNS Neurosci Ther (2012) 18:606-8. doi:10.1111/j.1755-5949.2012.00346.x

25. Kleindienst A, Brabant G, Bock C, Maser-gluth C, Buchfelder M. Neuroendocrine function following traumatic brain injury and subsequent intensive care treatment: a prospective longitudinal evaluation. J Neurotrauma (2009) 1446:1435-46. doi:10.1089/neu.2008.0601

26. Hohl A, Gullo Jda S, Silva CC, Bertotti MM, Felisberto F, Nunes JC, et al. Plasma levels of oxidative stress biomarkers and hospital mortality in severe head injury: a multivariate analysis. J Crit Care (2012) 27:523.e11-19. doi:10.1016/j.jcrc.2011.06.007

27. Mendes Arent A, de Souza LF, Walz R, Dafre AL. Perspectives on molecular biomarkers of oxidative stress and antioxidant strategies in traumatic brain injury. BioMed Res Int (2014) 2014:723060. doi:10.1155/2014/723060

28. Woiciechowsky C, Asadullah K, Nestler D, Eberhardt B, Platzer C, Chöning B, et al. Sympathetic activation triggers systemic interleukin-10 release in immunodepression induced by brain injury. Nat Med (1998) 4:808-13. doi:10.1038/ nm0798-808 
29. Dudás B, Mertchenthaler I. Close juxtapositions between LHRH immunoreactive neurons and substance $\mathrm{P}$ immunoreactiveaxons in the human diencephalon. J Clin Endoc Metabl (2002) 87:2946-53. doi:10.1210/jcem.87.6.8558

30. Coiro V, Volpi R, Capretti L, Caiazza A, Marcato A, Bocchi R, et al. Luteinizing hormone response to intravenous infusion of substance $\mathrm{P}$ in normal men. Metabolism (1992) 41:689-91. doi:10.1016/0026-0495(92)90305-T

31. Vink R, Gabrielian L, Thornton E. The role of substance P in secondary pathophysiology after traumatic brain injury. Front Neurol (2017) 8:304. doi:10.3389/fneur.2017.00304

32. Lorente L, Martín MM, Almeida T, Hernández M, Ramos L, Argueso M, et al. Serum substance $P$ levels are associated with severity and mortality in patients with severe traumatic brain injury. Crit Care (2015) 19:192. doi:10.1186/ s13054-015-0911-Z

33. Xiong Y, Mahmood A, Chopp M. Animal models of traumatic brain injury. Nat Rev Neurosci (2013) 14:128-42. doi:10.1038/nrn3407

34. Schwarzbold ML, Rial D, De Bem T, Machado DG, Cunha MP, dos Santos AA, et al. Effects of traumatic brain injury of different severities on emotional, cognitive, and oxidative stress-related parameters in mice. JNeurotrauma (2010) 27:1883-93. doi:10.1089/neu.2010.1318
35. Vink R. Large animal models of traumatic brain injury. J Neurosci Res (2017). doi:10.1002/jnr.24079

36. Meffre D, Pianos A, Liere P, Eychenne B, Cambourg A, Schumacher M, et al. Steroid profiling in brain and plasma of male and pseudopregnant female rats after traumatic brain injury: analysis by gas chromatography/mass spectrometry. Endocrinology (2007) 148:2505-17. doi:10.1210/en.2006-1678

Conflict of Interest Statement: The authors declare that the research was conducted in the absence of any commercial or financial relationships that could be construed as a potential conflict of interest.

Copyright (c) 2018 Hohl, Zanela, Ghisi, Ronsoni, Diaz, Schwarzbold, Dafre, Reddi, Lin, Pizzol and Walz. This is an open-access article distributed under the terms of the Creative Commons Attribution License (CC BY). The use, distribution or reproduction in other forums is permitted, provided the original author(s) and the copyright owner are credited and that the original publication in this journal is cited, in accordance with accepted academic practice. No use, distribution or reproduction is permitted which does not comply with these terms. 